\title{
Management of Bovine Eye Cancer with Autogenous Vaccine
}

\author{
M. Prasanna Lakshmi ${ }^{1}$, P. Veena ${ }^{1}$, R. V. Suresh Kumar ${ }^{1}$, D. Rani Prameela ${ }^{4}$, \\ K. Jagan Mohan Reddy ${ }^{1}$ and J. Veda Samhitha ${ }^{1}$ \\ ${ }^{1}$ Department of Veterinary Surgery and Radiology, India \\ ${ }^{2} S L D L$, SVVU, College of Veterinary Science, Tirupati, A.P., India \\ *Corresponding author
}

\section{A B S T R A C T}

\section{Keywords}

Bovine ocular squamous cell carcinoma, Surgical excision and autogenous vaccine

Article Info

Accepted:

27 April 2020

Available Online:

10 May 2020
Bovine ocular squamous cell carcinoma also called cancer eye, represents the most economically important neoplasm in large animals. Hereditary factors, environmental factors (e.g. latitude, altitude, exposure to sunlight), lack of eyelid pigmentation, age and dietary habits have all been reported to play a role in the etiopathogenesis of bovine ocular squamous cell carcinoma. Twenty four animals were subjected to surgical excision and autogenous vaccine was administered weekly once for four weeks. All the animals recovered completely with no recurrence for a follow up period of one year.

\section{Introduction}

Bovine ocular squamous cell carcinoma also called cancer eye, represents the most economically important neoplasm in large animals. Hereditary factors, environmental factors (eg: latitude, altitude, exposure to sunlight), lack of eyelid pigmentation, age and dietary habits have all been reported to play a role in the etiopathogenesis of bovine ocular squamous cell carcinoma. In addition, in cattle the etiology has been linked to a number of viral agents, especially bovine papilloma virus and bovine herpes virus type 1 and 5.

Different treatment options like hyperthermia in horses and cattle (Grier et al., 1980), surgical intervention followed by cauterization in cattle (Panchbhai et al., 1987), surgical excision followed by irradiation, cryotherapy in horses (King et al., 1991), and interleukin -2 (Otter et al., 1995) in bovines were tried in clinically affirmative cases of eye cancer without agreement in efficacy. 
The most common method of treatment is surgery and when combined with other treatment modalities, the success rates are quite good.

The study was done to report the cure and recurrence rate with following treatment of bovine eye cancer with surgical excision and autogenous vaccine.

\section{Materials and Methods}

The present study was conducted on 24 animals with cytologically diagnosed eye cancer. Routine clinical examinations were carried out and those that found to be fit for surgery and adjuvant treatment were utilized for the present study. Traumatic, infectious, inflammatory ocular conditions were excluded from the study.

Surgical excision of tumor was done under nerve blocks and sedatives by following aseptic precautions as per the standard procedure. The cancer tissue thus collected was used for autogenous vaccine preparation.

\section{Autogenous vaccine preparation}

Tumor mass was collected from the affected animals aseptically in PBS on ice until processing according to the method described by the Hunt (1984) at State Level Diagnostic Laboratory, SVVU, Tirupati.

The processing of tumors was carried out with sterile scissors, washed thoroughly with sterile PBS and homogenated with sterile sand using pestle and motor. Later $10 \%$ suspension was made with sterile PBS.

Then the suspension was centrifuged at 30000 $\mathrm{rpm}$ at $4^{\circ} \mathrm{C}$ for $30 \mathrm{~min}$ to remove the coarser particles. Supernatant was taken and formalin was added at a concentration of $0.5 \%$ to inactivate the virus. Vaccine thus prepared was added with equal volumes of aluminum hydroxide and left for 24 hours at $4{ }^{\circ} \mathrm{C}$ for sterility check-up of the vaccine samples were inoculated on blood agar, nutrient agar and mac conkey agar at $37^{\circ} \mathrm{C}$ for 48 hours. For fungal check-up the vaccine samples were inoculated on sabouraud dextrose agar media and kept in duplicates one at $37^{\circ} \mathrm{C}$ and another at $25^{\circ} \mathrm{C}$ for 3-7 days. After the sterility check-up the same animals with eye cancer were administered with the vaccine thus prepared.

\section{Vaccine dose and administration}

The adult animals were administered with 10 $\mathrm{ml}$ of vaccine subcutaneously weekly once for 4 weeks and observed for regression and recurrence of tumor.

\section{Results and Discussion}

Administration of autogenous vaccine caused complete recovery with no recurrence for a period of 6 months, with a success rate of $100 \%$ (Fig. 1). Panchbhai et al., (1989) and Bhume et al., (1992) observed complete cure after surgical excision followed by autogenous vaccine in ocular squamous cell carcinoma in cattle.

There was a significant relationship between the development of eye cancer and immunity. The disease mostly occurs in cattle which were immuno compromised. Since commercial vaccines for eye cancer in cattle were not effective in promoting regression or preventing malignant progression, autogenous vaccine was used for therapy that gives variable response. 

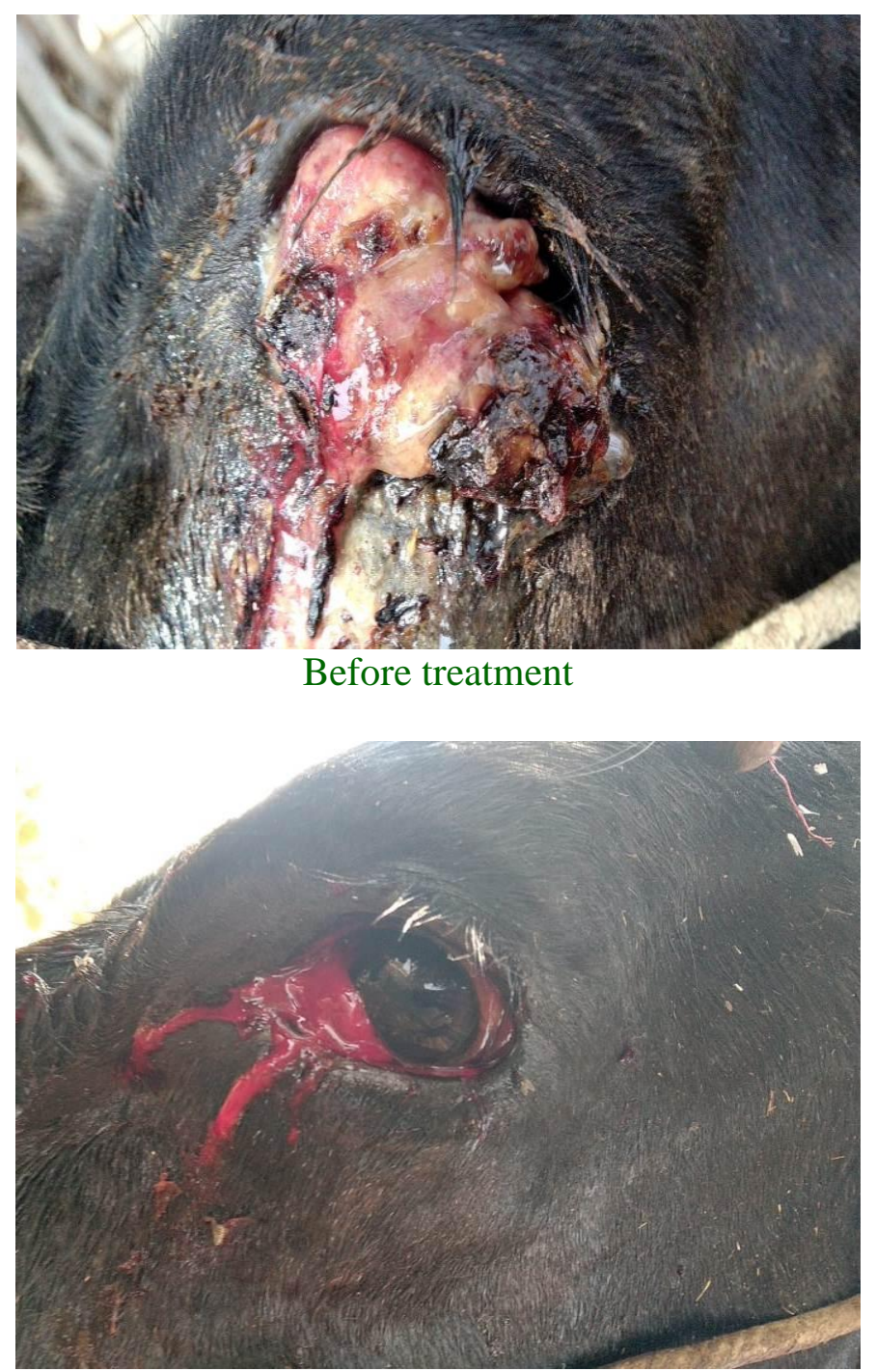

Immediately after surgery

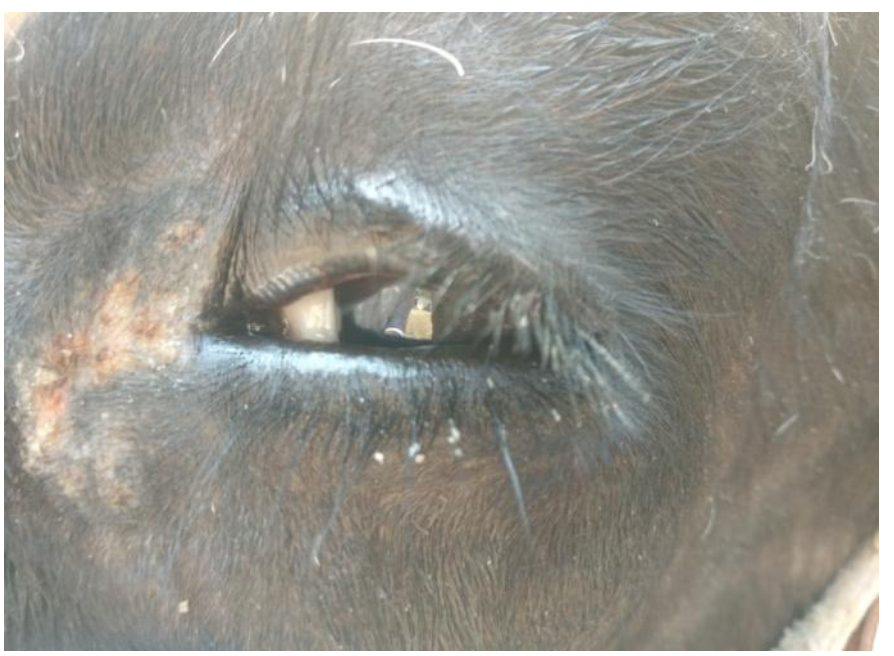

After 3 weeks of treatment with auto vaccine

Fig.1 Animal treated with surgery and autogenous vaccine 
On the basis of the observations, it was concluded that surgical excision is best in animals with large, extensive eye tumors with impaired vision. If facilities are available for preparation of autogenous vaccine, surgical excision and autogenous vaccine is best treatment in cattle with eye cancer with or without vision.

\section{References}

Bhume R I, Bhokre A P and Panchbhai V S 1992 Comparative evaluation of different therapies in bovine ocular squamous cell carcinoma. Indian Journal of Veterinary Surgery. 13(1): 16-17.

Grier R L, Brewer W G, Paul S R and Theilen G H 1980 Treatment of bovine and equine ocular squamous cell carcinoma by radiofrequency hyperthermia. Journal of the American Veterinary Medical Association. 177(1): 55-61.
Hunt E 1984 Fibropapillomatosis and papillomatosis. Veterinary Clinical of North America Large Animal Practice. 6: 163-167.

King T C, Priehs D R, Gum G G and Miller T R 1991 Therapeutic management of ocular squamous cell carcinoma in the horse: 43 cases (1979-1989). Equine Veterinary Journal. 23(6): 449-452

Otter W D, Hill FW G, Klein W R, Koten J W, Steerenberg P A, De Mulder P H M, Rhode C, Stewart R, Faber J A J, Ruitenberg E J and Rutten V P M G 1995 Therapy of bovine ocular squamous cell carcinoma with local doses of interleukin-2: $67 \%$ complete regressions after 20 months of follow up. Cancer Immunology and Immunotherapy. 41: 10-14.

Panchbhai V S, Kulkarni P E and Deshpande B B. 1987 Some observations on ocular growths in cattle. Indian Veterinary Journal. 64: 29-32.

\section{How to cite this article:}

Prasanna Lakshmi, M., P. Veena, R. V. Suresh Kumar, D. Rani Prameela, K. Jagan Mohan Reddy and Veda Samhitha, J. 2020. Management of Bovine Eye Cancer with Autogenous Vaccine. Int.J.Curr.Microbiol.App.Sci. 9(05): 2734-2737. doi: https://doi.org/10.20546/ijcmas.2020.905.313 